\title{
VIGOTSKI E LEONTIEV: DE MEMÓRIAS E SENTIDOS
}

\author{
VIGOTSKI E LEONTIEV: DE MEMÓRIAS E SENTIDOS
}

Este número de Cadernos Cedes, intitulado "Vigotski e Leontiev: De memórias e sentidos", baseia-se na tradução do segundo "Prefácio" escrito por Vigotski ${ }^{1}$, em coautoria com A. N. Leontiev, ao livro O desenvolvimento da memória (LEONTIEV, [1931]2003; 2020, neste dossiê). A leitura de tal texto instigou a primeira organizadora do dossiê a encaminhar sua tradução ${ }^{2}$ e, na companhia de Ana Luiza B. Smolka, mediar a difusão e apropriação do mesmo no Brasil. Ao que se sabe, trata-se da primeira tradução desse texto do russo para qualquer outro idioma. Originalmente, o segundo "Prefácio" fora publicado como folheto à parte, acompanhando os exemplares da primeira edição do livro em questão, já impressos, conforme esclarecem em nota A. A. Leontiev, D. A. Leontiev e E. E. Sokolova, editores russos dos trabalhos jovens de A. N. Leontiev (ver LEONTIEV, 2003). O primeiro "Prefácio" ao referido livro foi escrito apenas por Vigotski e incluído nas Obras Escolhidas em russo, apresentando-se também em suas subsequentes traduções, em espanhol (VYGOTSKI, 1991), em português (VIGOTSKI, 1996) e em inglês (VYGOTSKY, 1997).

Entre 1929 e 1932, estava em curso, na URSS, o período que deu início à exclusão das alternativas à autocracia stalinista, a Grande Quebra, como diria o próprio Stalin (TOASSA, 2016). Críticas públicas aos cientistas mesclavam questionamentos de teor político e intelectual. É pouco conhecida, em nosso contexto, a autocrítica contida no "Prefácio", de que nos deu notícia uma conversa com o historiador ucraniano Anton Yasnitsky $^{3}$, a qual foi realizada pelos seus autores no referido período.

Que Vigotski e Leontiev tenham julgado necessário escrever novo prefácio à primeira edição de uma obra apenas dois anos após terminada é questão, por si só, merecedora de investigação histórica. Coube a vários autores do presente dossiê aventar quais teriam sido as razões para tal escolha, pois não há indícios de pressões políticas diretas para que o fizessem. Como o segundo "Prefácio" endereça-se, especialmente, embora não exclusivamente, aos temas sentido (smysl) e memória (pámyat), consideramos que esses conceitos deveriam intitular nosso dossiê. Apesar disso, consideramos essencial tratar o "Prefácio" como "estrutura prismática", a refratar a luz do pensamento de Vigotski e Leontiev em diferentes comprimentos de onda: das neurociências, da educação, da psicologia e da arte. Assim, fazemos jus à natureza interdisciplinar da obra desses autores, tendo em perspectiva o diálogo com leitores de diferentes áreas do conhecimento.

Outros motivos, originários do campo das ideias científicas, levam-nos a propor um debate mais amplo sobre memória e sentido. Tanto Danziger (2003) quanto Lima (2005) testemunham a profusão de ideias teóricas sobre o conceito de memória no decorrer do século XIX, profusão essa, segundo Lima, seguida de um relativo desprestígio da memória como objeto de pesquisa, em benefício da atenção. Fundamentando-se em pesquisas dos mais diversos campos, Carr (2011) justifica a decadência teórica da memória como processo tipicamente humano e social, que se desenvolve tanto inter- quanto intrapsicologicamente, graças ao aumento explosivo da memória digital. É nesse contexto que urge pensar a unidade - aparentemente negligenciada em produções mais recentes - entre memória e sentido como processos sócio-históricos. 
Os três primeiros textos que integram o dossiê, após a tradução do "Prefácio", apresentam interpretações de caráter teórico e histórico. Anton Yasnitsky, atualmente radicado no Canadá, falanos, em seu artigo "Aleksei N. Leontiev's research on memory and its meaning as the soviet avant-garde science of the future", de sua visão da história e do lugar de Leontiev e de seu livro Razvitie pamiati [O desenvolvimento da memória] no Círculo Vigotski-Luria-Leontiev, comentando sobre as relações entre esses pesquisadores nas décadas de 1920 e 1930. O autor faz menção ao subsequente desenvolvimento das ideias, por Leontiev e seus colegas, após a morte de Vigotski, discutindo as posições e as interrelações desses três protagonistas, descritos na narrativa canônica como uma troika que teria criado a psicologia históricocultural. Contra-argumentando que os três autores se mantiveram relativamente unidos aproximadamente entre 1926 e 1930, Yasnitsky afirma que eles não chegaram a compor uma verdadeira troika, indicando que o rótulo "histórico-cultural" emergiu nas discussões críticas sobre os estudos de Vigotski e Luria no início dos anos 1930. Yasnitsky ressalta que Leontiev apresentou dados consideráveis e generalizações teóricas no estudo sobre memória, os quais refletem o estado da arte na emergente teoria de Vigotski no final de 1929. Inaugurando polêmicas e levantando controvérsias, esse texto convida ao debate de ideias, ao aprofundamento conceitual e à inesgotável pesquisa histórica. Nessa direção seguem os demais textos do dossiê.

No artigo "Factual and theoretical status of the memory development parallelogram", o russo Boris Meshcheryakov apresenta e discute a polêmica sobre o "paralelogramo do desenvolvimento da memória" na Rússia do século XXI. O "paralelogramo", extensivamente discutido no livro O desenvolvimento da memória, é um nome atribuído por A. N. Leontiev à representação gráfica dos resultados de seu estudo macroontogenético (estudo transversal) de memorização, mediada e não mediada, de palavras; ou seja, memorização de palavras com e sem figuras auxiliares (LEONTIEV, 2003). Dado seu caráter pioneiro, por muito tempo, o paralelogramo do desenvolvimento da memória foi visto como representação inquestionável. Todavia, desde a década de 1990, nos principais periódicos russos de psicologia, várias publicações negaram o paralelogramo do desenvolvimento da memória como um fato real. Meshcheryakov sai em defesa de Leontiev, ao sustentar que o paralelogramo teria um caráter metafórico, não pretendendo esgotar a representação gráfica das transformações ocorridas na memória mediada de acordo com a idade. O artigo de Meshcheryakov mostra-se importante para podermos, no contexto brasileiro, compreender melhor as sutilezas metodológicas da pesquisa sobre memória, mostrando que, tal como Vigotski e Leontiev (2020, neste dossiê) problematizam em seu "Prefácio", não se pode atribuir à memória um funcionamento puramente mecânico.

No terceiro texto, "Análise teórico-histórica das produções de Leontiev e Vigotski acerca do desenvolvimento da memória", Sandro Henrique Vieira de Almeida narra que os estudos sobre memória na psicologia histórico-cultural foram inicialmente desenvolvidos entre os anos de 1927 e 1932, concordando com Yasnitsky acerca da importância de Leontiev para esse tema, embora admitindo, ao contrário do autor ucraniano, o compartilhamento dos fundamentos epistemológicos e investigativos da troika VigotskiLuria-Leontiev. De outro ponto de vista, Almeida apresenta os experimentos sobre memória traçando os fundamentos materialistas propostos por eles, com destaque para a inovação metodológica contida no uso de palavras dotadas de sentido e instrumentos auxiliares. De maneira criteriosa, Almeida pontua os problemas identificados pelos autores do "Prefácio" na realização das pesquisas sobre a memória humana, comentando sobre as dificuldades por eles encontradas na superação de uma visão dualista, idealista ou mecanicista, ressaltando as proposições e o constante questionamento dos mesmos na elaboração de uma psicologia fundada no materialismo histórico e dialético.

O texto seguinte, "Contribuições dos estudos de autores soviéticos para a psicologia e a neurociência cognitiva contemporâneas", produz-se a partir da neurociência, um dos campos em que 
as contribuições da obra de Luria e Vigotski disseminaram-se mundialmente. O autor, Benito Pereira Damasceno, neurologista brasileiro que vem desenvolvendo estudos sobre memória há vários anos, tendo como referência a perspectiva histórico-cultural, coloca em destaque, uma das mais relevantes contribuições dos autores soviéticos: a elaboração do conceito de "sistema funcional complexo" (SFC) como forma de funcionamento sistêmico, distribuído e dinâmico, de qualquer atividade mental (p. ex., percepção de um objeto, resolução de um problema, enunciação discursiva). Esse conceito, introduzido e desenvolvido inicialmente por P. Anokhin, aluno de Pavlov, constituiu contribuição fundamental para as investigações realizadas por Vigotski ([1934]1996), Leontiev (1981), e, principalmente, Luria, em seus estudos neuropsicológicos ([1966]1980). O SFC é concebido como a representação tanto psíquica (abstrata) como cerebral (corporal) da atividade externa (p. ex., trabalho produtivo), com a qual constituem uma unidade funcional. A partir dessa perspectiva, Damasceno discute como os avanços da neuropsicologia e da neurociência cognitiva têm confirmado, cada vez mais, essa estrutura sistêmica e dinâmica da atividade mental. Os estudos de neuropsicologia e neurociência têm demonstrado que cada subtipo de memória é, por sua vez, um complexo sistema funcional.

No artigo "O jogo dos sentidos: Estruturas duplas da arte e a categoria do sentido em Vigotski", Priscila Nascimento Marques argumenta sobre a potencialidade dos escritos de Vigotski, ressaltando o esforço do autor de reestruturar, teórica e metodologicamente, o campo de intersecção entre psicologia e arte. Propondo-se a examinar a ideia de "sentido" em textos escolhidos do autor russo - A tragédia de Hamlet, Príncipe da Dinamarca, resenhas jornalísticas do período de 1922 e 1923, e Psicologia da arte -, suas análises exploram, assim, possíveis acepções da noção de sentido na obra de Vigotski, indicando nuanças, especificidades e relações entre arte, pensamento e palavra. Ao voltar-se para os meandros da produção de Vigotski na década de 1920, dando visibilidade ao movimento de elaboração teórica do autor - entre a carga mística do simbolismo e a arte como técnica social do sentimento -, Marques contribui para inspirar novas veredas de estudo e perspectivas de análise das relações entre memória e sentido.

Gisele Toassa, em seu artigo "Um estudo sobre o conceito de sentido e a análise semântica da consciência em L. S. Vigotski”, trata da relação sentido-significado (smisl-znatchenie), equivalente à "análise semântica ou semasiológica" da consciência em diferentes obras de Vigotski, com atenção particular ao capítulo final do livro Pensamento e linguagem ([1934]2001). Tal relação vem se disseminando há algumas décadas na psicologia sócio-histórica/histórico-cultural brasileira, tomando grande importância em estudos teóricos e empíricos. Toassa sustenta que o conceito de "sentido" tem uma acepção filosófica mais geral, para além do conteúdo simbólico que se evidencia no "Prefácio". A autora nos convida a uma reflexão sobre o conteúdo existencial e político desse conceito, além de problematizar criticamente a faceta linguística da análise semântica. Toassa situa essas considerações no contexto de sua pesquisa sobre a especificidade do materialismo marxista de Vigotski, processo no qual o sentido será desmembrado em cinco núcleos semânticos básicos: formação (obrazovanie), relação/conexão, orientação, inteligibilidade e "zona” semântica, composta por outras zonas, ou seja, núcleos internos de significação.

No último texto, intitulado "Memória e sentido na narrativa de crianças: Inspirações vigotskianas para a pesquisa na escola", o "Prefácio" constitui o mote para o aprofundamento das discussões que Elizabeth dos Santos Braga e Ana Luiza Bustamante Smolka trazem ao presente dossiê. Transitando da teoria à empiria, as autoras discutem ideias e conceitos nele apresentados, destacando o problema da semântica (a significação, a produção de signos e sentidos) e o problema da idade (relacionado ao problema do meio, à situação social de desenvolvimento), pontos fundamentais da autocrítica de Vigotski e Leontiev nos estudos da memória. Argumentando sobre a natureza social da memória e seu papel na constituição da personalidade, Braga e Smolka referem-se a um projeto de intervenção e investigação realizado em 
uma escola pública de São Paulo, do qual participaram crianças do Ensino Fundamental, seus professores e professoras, assim como familiares e outros sujeitos que conviviam na comunidade escolar. Ancoradas na ideia do sistema funcional complexo, e tomando as narrativas das crianças tanto como lócus de análise quanto como lócus de constituição da memória, as autoras dão visibilidade às relações entre memória, afeto, significação e forma verbal de linguagem, enquanto mobilizam o conceito de perezhivanie, da vivência atribuída de sentido.

Companhias virtuais para os(as) leitores(as) no processo de exploração de novos e tradicionais conceitos da teoria histórico-cultural, desejamos-lhes boas leituras!

\section{Notas}

1. Adotamos, neste Dossiê, a grafia “Vigotski” sempre que se fizer referência ao nome do autor, sem, necessariamente, citá-lo. As citações, no corpo do texto, utilizarão grafia idêntica às referências ao fim dos artigos, podendo a grafia do nome deste autor apresentar-se como Vigotskii, Vygotsky ou Vygotski, a depender da grafia empregada na obra referenciada.

2. Tradução de Gisele Toassa, Yuliya Kodalyeva e Priscila Nascimento Marques.

3. Nascido na Ucrânia, Anton Yasnitsky obteve seu PhD no Ontario Institute for Studies in Education, University of Toronto (Canadá). Continua trabalhando como pesquisador independente na mesma cidade.

\section{REFERÊNCIAS}

CARR, N. The shallows: What the Internet is doing to our brains. New York: WW Norton \& Company, 2011.

DANZIGER, K. Where theory, history and philosophy meet: The biography of psychological objects. In HILL, D. B.; KRAL, M. J. (eds.). About psychology: Essays at the crossroads of history, theory and philosophy. New York: New York University Press, 2003, p. 19-33.

LEONTIEV, A. N. (1931). O desenvolvimento da memória [Razvitie pamiati]. In: LEONTIEV, A. N. Stanovlenie psikhologuii deiatelnosti: Rannie raboti. Moscou: Smisl, 2003, p. 28-225.

LIMA, R. C. Somos todos desatentos. O TDA/H e a construção de bioidentidades. Rio de Janeiro: Relume Dumará, 2005.

TOASSA, G. Nem tudo que reluz é Marx: Críticas stalinistas a Vigotski no âmbito da ciência soviética. Psicologia USP, v. 27, n. 3, p. 553-563, 2016. https://doi.org/10.1590/0103-656420140138

VIGOTSKI, L. S. (1934). Desenvolvimento da memória. Prefácio ao livro de A. N. Leontiev. Teoria e método em Psicologia. Trad. Paulo Bezerra. São Paulo: Martins Fontes. 1996, p. 161-170.

VIGOTSKI, L. S. (1931). A construção do pensamento e da linguagem. São Paulo: Martins Fontes, 2001.

VIGOTSKI, L. S.; LEONTIEV, A. N. (1932). Prefácio ao livro de A. N. Leontiev O desenvolvimento da memória" [Predisloviye k knige A.N. Leont'yeva «Razvitiye pamyati»]. In: LEONTIEV, A. N. Stanovlenie psikhologuii deiatelnosti: Rannie raboti. Moscou: Smisl, 2003, p. 199-205. 
VYGOTSKI, L. S. (1931) Prólogo al libro de A. N. Leontiev “Desarrollo de la memoria”. Obras Escogidas. Madrid: Visor Distribuiciones, 1991, v. 1, p. 111-117.

VYGOTSKY, L. S. (1931) Preface to Leontiev. In: RIEBER, R. W.; WOLLOCK, J. (eds.), The collected works of L. S. Vygotsky. V. 3: Problems of the theory and history of psychology. New York: Plenum Press, 1997, p. 123-128.

1.Universidade Federal de Goiás - Faculdade de Educação - Goiânia (GO), Brasil.

2.Universidade Estadual de Campinas - Faculdade de Educação - Campinas (SP), Brasil.

*Autora correspondente: gtoassa@gmail.com

Comitê Editorial do Cedes/Coordenação deste número: Silvia Cordeiro Nassif/Maria Silvia Pinto de Moura Librandi da Rocha 